\title{
Guías de forasteros en la cultura de las formas impresas: Hispanoamérica [1761-1893]
}

Resumen: Este artículo propone el estudio de la cultura de las formas impresas en Hispanoamérica entre 1761 y 1893 a partir del análisis histórico de la producción de las guías de forasteros. Con este propósito se revisa la legislación en torno a la impresión de libros y papeles, los ritmos y ciclos de producción de las guías de forasteros y la relación de los impresores y editores con proveedores de información para la elaboración de dichas guías. El enfoque principal de este estudio es la historia cultural, en particular, de las formas impresas, a partir de la propuesta del "circuito de comunicaciones" de Robert Darnton.

Palabras clave: guías de forasteros, almanaques, historia del libro, América hispana, cultura impresa.

\section{Foreigners guides in the culture of printed forms: Spanish America [1761-1893]}

Abstract: This article proposes the study of the print culture in Spanish America between 1761 and 1893 , based on the historical analysis of the production of foreigners guides. The article offers a review of the legislation regarding the printing of books and papers, the rhythms and cycles of production of foreigners guides and the relationship of printers and publishers with information providers for the preparation of such guides. The main focus of this study is the cultural history of print, based on Robert Darnton's "communications circuit".

Keywords: foreigners guides, almanacs, book history, Spanish America, print culture.

\section{Guias de forasteiros na cultura das formas impressas: América hispânica [1761-1893]}

Resumo: Este artigo propõe o estudo da cultura impressa na América hispânica entre 1761 e 1893, com base na análise histórica da produção dos guias de forasteiros. Com esse fim, estuda-se a legislação referente à impressão de livros e papéis, os ritmos e ciclos de produção dos guias de forasteiros e a relação de impressores e editores com provedores de informação para a elaboração dos guias. A abordagem principal deste estudo é a história cultural, principalmente das formas impressas, a partir da proposta do "circuito de comunicações" de Robert Darnton.

Palavras-chave: guias de forasteiros, almanaques, história do livro, América hispânica, cultura impressa.

Cómo citar este artículo: Lina Cuellar Wills, "Guías de forasteros en la cultura de las formas impresas: Hispanoamérica [1761-1893]”, Trashumante. Revista Americana de Historia Social 16 [2020]: 170-191.

DOI: 10.17533/udea.trahs.n16a09

Fecha de recepción: 10 de septiembre de 2019

Fecha de aprobación: 2 de abril de 2020

Lina Cuellar Wills: Doctora en Historia por la Universidad de Los Andes y profesora de cátedra de la Universidad Jorge Tadeo Lozano.

Correo electrónico: I.cuellar86@uniandes.edu.co 


\title{
Guías de forasteros en la cultura de las formas impresas. Hispanoamérica [1761-1893]
}

\author{
Lina Cuellar Wills
}

\section{Introducción}

$\mathrm{D}$

urante el periodo de las reformas borbónicas circularon en América hispana unos impresos llamados guías de forasteros, cuyo objetivo principal era dar cuenta de la estructura burocrática de los virreinatos. Su existencia se registra desde 1761 con la Guia para que las personas que tuviesen negocios sepan las casas de los sujetos que obtienen empleos en los tribunales y juzgados de ella, impresa en México por Felipe de Zúñiga y Ontiveros, y que se sostiene por más de 130 años hasta 1893 cuando se publica la Guía práctica de la Capital para el comercio, pasajeros, forasteros del colombiano José Manuel Patiño. A pesar de que el nombre pueda hacer creer que eran textos para viajar y recorrer ciudades, las guías de forasteros eran impresos de consulta rápida de listados de nombres de funcionarios y oficinas en los que, además, se incluía generalmente un almanaque al inicio. Este corpus de guías, que suman un poco más de 200 y conforman un género editorial, constituyen un caso representativo de la cultura de las formas impresas en Hispanoamérica. ${ }^{1}$

La producción, existencia, circulación y usos de impresos en Hispanoamérica indica que, como cualquier otro producto de consumo durante los siglos XVIII y XIX, formaban parte de los mercados locales y regionales. Por lo tanto, no es de extrañar que aparecieran involucrados en estas dinámicas impresores, tipógrafos, cajistas, fabricantes de papel, vendedores de diferentes niveles sociales y lectores. El objetivo de este artículo es analizar cuál fue el lugar del género de las guías de forasteros en la cultura de las formas impresas en Hispanoamérica entre $1761 \mathrm{y}$ 1893 y cómo su edición, impresión y usos formaban parte de prácticas ya comunes para este periodo. Para tal fin, abordaré la propuesta del circuito de comunicaciones de Robert Darnton, que explica cómo los impresos existen en tanto forman parte de una cadena que involucra agentes en diferentes ámbitos y actividades de

1. Para un estudio introductorio de las guías de forasteros, véase Lina Cuellar Wills, "Hacia una definición y caracterización de las guías de forasteros en América hispana, 1761-1893", Anuario Colombiano de Historia Social y de la Cultura 46.1 (2019): 85-122. 
la sociedad en la que se producen: el autor o editor, el impresor, los proveedores de materiales, los libreros y los lectores (Figura 1). La idea central de este circuito es demostrar que la existencia de un impreso no está dada solo por el hecho de haber pasado por una imprenta, sino también por las relaciones que su producción estableció entre grupos e individuos que, a su vez, estaban afectados por las circunstancias sociales, políticas, económicas y culturales de su tiempo. ${ }^{2}$

Figura 1. Circuito de comunicaciones para el análisis de las guías de forasteros

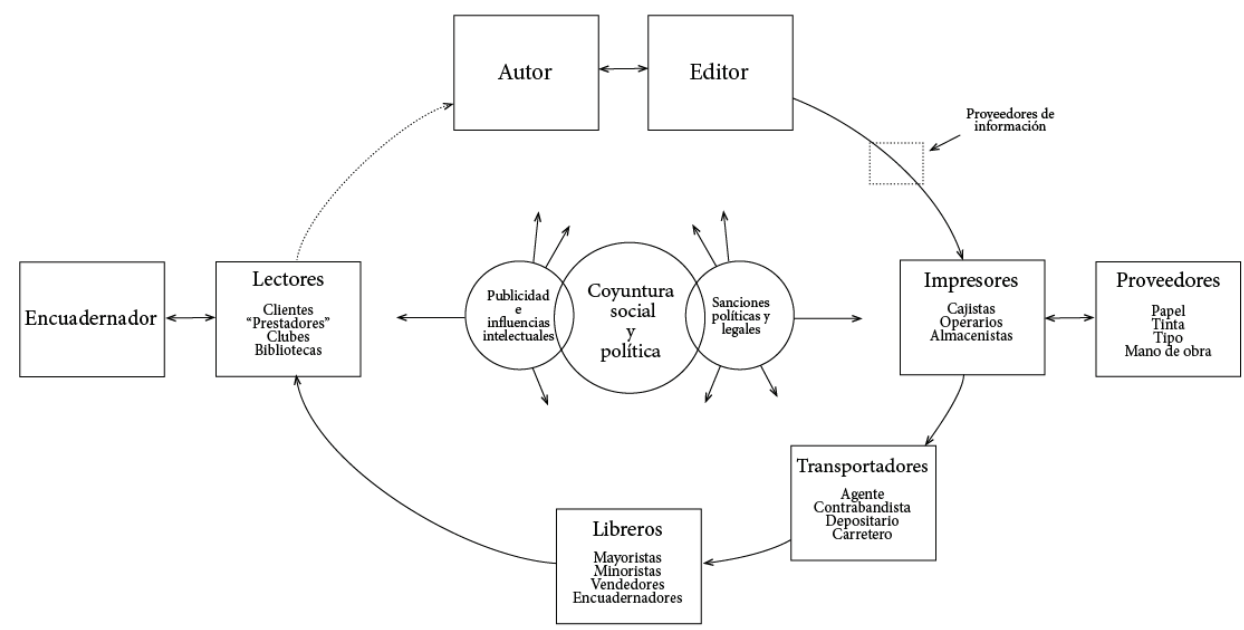

Fuente: Circuito de comunicaciones propuesto por Darnton, con un añadido propio (proveedores de información) para el análisis de las guías de forasteros. Darnton 68.

Darnton propone este modelo para considerar la variedad de elementos que intervienen en la producción y circulación de los impresos, que empieza por el autor y regresa a este después de varias "estaciones". Sin embargo, en este circuito destaca también un hecho palpable en el análisis histórico de la cultura impresa, en el caso de las guías de forasteros, relacionado con el tipo de fuentes y documentos en donde puede encontrarse la información requerida para construirlo. Los archivos de los editores y de los impresores son una fuente rica en información, y aun así esquivos y difíciles de encontrar. El mismo Darnton señala cómo, quienes desempeñaban estos oficios, trataban sus propios archivos como material desechable durante los siglos XVIII y XIX. ${ }^{3}$ Por esta razón, para comprender cómo se componía el circuito de comunicaciones en la producción de guías de forasteros, dada la dificultad de acceso a archivos privados de impresores y editores, se utilizaron fuentes alternativas como la prensa en la cual hay noticias, avisos o comentarios

2. Robert Darnton, "What Is the History of Books?", Daedalus 111.3 (1982): 65-83.

3. Darnton 76-77. 
con relación a la recolección de información, venta, edición de impresos y respuestas de los lectores.

Los editores / autores de las guías de forasteros establecieron diálogos con otros impresos, con los lectores y con los proveedores de información para poder completarlas. Su proceso de producción involucraba agentes de diferentes círculos comerciales y sociales, lo que permitió que las guías formaran parte de las dinámicas de la cultura del impreso y de lo escrito en Hispanoamérica. Recopilar información era solo una parte de la larga cadena de requisitos, posibilidades y recompensas (o fracasos) que traía comprometerse con la edición de las guías de forasteros. En consecuencia, al modelo de Darnton se le ha añadido un agente más que se denominó “proveedores de información”, esencial para editar las guías de forasteros. Este aspecto específico se analizará detalladamente más adelante.

El "circuito de comunicaciones" de Darnton propone mirar el funcionamiento de los impresos en su conjunto y vincularlos con diferentes campos de conocimiento que están concentrados en el problema común de la comunicación. ${ }^{4}$ Por lo tanto, se involucra una mirada sociológica e histórica a los procesos de diseminación de los impresos y a la participación de agentes que en apariencia parecieran tener poca relación con los textos y con la lectura: los impresores, los vendedores o los espacios de sociabilidad. El análisis histórico de las guías de forasteros comprende un estudio en el que inevitablemente aparecen aspectos del funcionamiento de este mercado, pues en buena parte la permanencia de las guías se debió a un auge editorial mucho más amplio iniciado en Europa en el cual "los libreros-editores más audaces se inventaron un mercado popular de lo impreso". 5

\section{Algunos aspectos de la cultura impresa hispanoamericana}

El mercado de los impresos en Hispanoamérica durante el siglo XVIII se desarrolló como consecuencia de la necesidad de estructurar ciudades centralizadas en las que la palabra impresa diera orden a la sociedad y sus dinámicas. Los “dueños de la letra", las élites, pertenecían a un sistema de institucionalización que iba desde las academias y universidades hasta las dependencias administrativas y burocráticas de los gobiernos virreinales. ${ }^{6}$ Las imprentas fueron artefactos que trajeron a los territorios americanos, por una parte, la posibilidad de multiplicar y ampliar el alcance del conocimiento y de la información y, por otra parte, establecer una compleja red de agentes cuyo trabajo e intereses giraban en torno a la producción, circulación y usos de impresos de diferente índole: folletos, novenas, esquelas, documentos oficiales, almanaques, cartillas y, entre otros, guías de forasteros. La imprenta tuvo un rol importante en el desarrollo de nuevas sociabilidades en los albores de

4. Darnton 65.

5. Roger Chartier, "Lecturas y lectores 'populares' desde la época clásica hasta el Renacimiento", Historia de la lectura en el mundo occidental, dirs. Guglielmo Cavallo y Roger Chartier (México: Taurus, 2012) 338.

6. Ángel Rama, La ciudad letrada (Santiago: Tajamar Editores, 2004) 57. 
las revoluciones hispanoamericanas, así como en el periodo de posindependencia, cuando esta sirvió en el establecimiento de los nuevos órdenes políticos y administrativos de las repúblicas. ${ }^{7}$

Además, el comercio de libros se dio en América desde los primeros años de la conquista y del periodo colonial tal como lo atestiguan inventarios de bibliotecas privadas, registros de entrada de impresos de España a América, expedientes de mercaderes y testamentos. Los impresos de mayor demanda trataban temas religiosos, científicos, históricos y de literatura popular, aunque no se restringían únicamente a estas materias. ${ }^{8}$ Por lo tanto, la circulación de libros y papeles no era nueva para la segunda mitad del siglo XVIII, aunque sí se experimentó durante esta época un aumento en la producción de impresos con la aparición de talleres tipográficos en algunas de las principales ciudades de los virreinatos como: Quito (1759), Santiago de Chile (1776), Buenos Aires (1780), Guadalajara (1793), Veracruz (1794) y Santiago de Cuba (1796), entre otras.

El funcionamiento de las imprentas requería de una cantidad importante de agentes, entre quienes se contaban editores, cajistas, proveedores, distribuidores y lectores. Tal como se observa en el modelo de circuito de comunicaciones de Darnton, es difícil creer que los libros y papeles dependían únicamente de los autores y de otros pocos individuos, cuando en realidad existía una relación de dependencia que involucraba mercados, legislaciones y prácticas de lectura. Entre la información que puede extraerse de las guías de forasteros sobre la cultura del impreso está la permanente marca que las imprentas dejaron en ellas, que va desde la aparición del nombre del taller en la página del título hasta la calidad y las características del soporte material. Incluso es posible determinar cuál fue la continuidad o periodicidad de impresión de las guías de forasteros, lo que muestra la permanencia de la imprenta misma en las dinámicas de los crecientes mercados desde finales del siglo XVIII y durante el XIX.

Los talleres que imprimieron guías de forasteros fueron negocios particulares o entidades que formaban parte de instituciones apoyadas por la oficialidad. Una revisión detallada de cuáles fueron los establecimientos que publicaron guías de forasteros en el periodo comprendido entre 1761 y 1893 muestra dos aspectos relevantes. Primero, los talleres que produjeron un mayor número de guías fueron aquellos en los que estos impresos eran encargados por los gobiernos; es decir, eran productos oficiales y por lo tanto promovidos por los virreinatos o gobiernos de las repúblicas independientes. Segundo, no se ha encontrado evidencia de que se publicara un número significativo de guías de forasteros en un mismo territorio, país o ciudad para el mismo año antes del periodo republicano. Esta situación

7. François-Xavier Guerra y Annick Lempérière, "Introducción”, Los espacios públicos en Iberoamérica. Ambigüedades y problemas, siglos XVIII y XIX, eds. François-Xavier Guerra y Annick Lempérière (México: Centro Francés de Estudios Mexicanos y Centroamericanos / Fondo de Cultura Económica, 1998) 17.

8. Pedro M. Guibovich Pérez, "Los espacios de los libros en el Perú colonial", Lexis XXVIII.1-2 (2003): 185-186. 
cambia levemente en 1834 en Perú, cuando aparecen guías de forasteros para Lima, Trujillo y Cuzco para ese mismo año, y más adelante en México, en 1852, cuando se imprime una guía para Puebla y otra para la capital simultáneamente. ${ }^{9}$ En consecuencia, fue común que un solo taller tuviera la exclusividad de imprimir las guías de forasteros para el virreinato o la capital y, por lo tanto, que se creara un monopolio fácilmente identificable.

En la Tabla 1 se detallan las imprentas que publicaron al menos dos guías de forasteros entre 1761 y 1893 en Hispanoamérica.

De las 70 guías restantes que no aparecen en esta lista, 21 no especifican el taller en que se publicaron y 49 , correspondiente al 23\%, salieron una vez de diferentes empresas particulares o institucionales. Según los registros encontrados, el $42 \%$ de la producción de guías en Hispanoamérica estuvo monopolizado por dos imprentas institucionalizadas (la Imprenta de Niños Expósitos en Perú y la Imprenta de la Capitanía General de La Habana) y dos privadas (el taller de los Zúñiga y Ontiveros en México y el de José Masías en Perú). Esto muestra el privilegio de dichos establecimientos en el mercado de las guías de forasteros en los tres territorios donde más se publicaron (México, Perú y Cuba). Además, de estos cuatro talleres, tres iniciaron labores a finales del siglo XVIII, lo que establece una relación entre la producción de guías y el privilegio de impresión que la legislación del antiguo régimen español estableció al respecto.

Tampoco es gratuito que tres de las cuatro imprentas que tuvieron monopolios de producción de las guías de forasteros estuvieran en los dos virreinatos que primero tuvieron imprenta en América: Nueva España (1539) y Perú (1584). La relación entre guías de forasteros, monopolio de las imprentas y control gubernamental sirve para explicar por qué en estos dos territorios se produjo un mayor número de guías y qué tanto estaban controladas por los gobiernos. El hecho de que las guías de forasteros surgieran durante las reformas borbónicas por privilegio otorgado a ciertas imprentas e impresores se explica con la "política cultural del absolutismo" por medio de la cual la Corona española se valió de los impresos para circular sus disposiciones, reglamentos y políticas de carácter público: se trataba de una forma de regulación y de difusión de esos mecanismos de control y del proyecto de civilización borbónico. ${ }^{10}$

Existe una diferencia importante entre las imprentas institucionales y las de carácter privado: las primeras, como en el caso de la de Niños Expósitos con sedes en Lima y en Buenos Aires, tenían como fin reproducir material de los gobiernos para obtener ganancias que se destinarían al sostenimiento de la imprenta, de sus operarios y a aportar a la beneficencia relacionada con su nombre. Por el contrario, las imprentas privadas eran negocios particulares que producían desde esquelas, invitaciones y almanaques hasta informes y manuales cuyo privilegio o exclusividad

9. Cuellar Wills 111-122.

10. Renán Silva, Los ilustrados de Nueva Granada, 1760-1808. Genealogía de una comunidad de interpretación (Bogotá: Banco de la República / Fondo Editorial Eafit, 2002) 273. 
Tabla 1. Lista de las imprentas que publicaron al menos dos guías de forasteros entre 1761 y 1893 en Hispanoamérica

\begin{tabular}{|c|c|c|c|c|}
\hline Imprenta & Lugar & Tipo & Fechas & Cantidad \\
\hline $\begin{array}{l}\text { Felipe y Mariano } \\
\text { Zúñiga y Ontiveros }\end{array}$ & México & Privada & $1763-1820$ & 32 \\
\hline Mariano Galván` & México & Privada & 1826-1835 & 3 \\
\hline Miguel Corona & México & Privada & $1843-1853$ & 2 \\
\hline $\begin{array}{l}\text { Imprenta Real / } \\
\text { Imprenta de Niños } \\
\text { Expósitos / de los } \\
\text { Niños Huérfanos }\end{array}$ & Perú & Institucional & 1781-1819 & 20 \\
\hline Imprenta de Ruiz & Perú & Privada & 1815-1817 & 3 \\
\hline Imprenta del Estado & Perú & Institucional & $1821-1872$ & 6 \\
\hline José Masías & Perú & Privada & $1830-1863$ & 14 \\
\hline $\begin{array}{l}\text { Imprenta de } \\
\text { Instrucción primaria }\end{array}$ & Perú & Institucional & $1827-1846$ & 8 \\
\hline $\begin{array}{l}\text { Imprenta de la } \\
\text { Capitanía General / } \\
\text { Imprenta de Gobierno } \\
\text { y Capitanía General }\end{array}$ & Cuba & Institucional & $1781-1883$ & 23 \\
\hline $\begin{array}{l}\text { Imprenta Real de los } \\
\text { Niños Expósitos }\end{array}$ & Argentina & Institucional & $1791-1803$ & 2 \\
\hline Wenceslao Solveyra & Argentina & Privada & 1864-1867 & 5 \\
\hline $\begin{array}{l}\text { Antonio y Bruno } \\
\text { Espinosa de los } \\
\text { Monteros }\end{array}$ & Colombia & Privada & 1793-1805 & 3 \\
\hline Ignacio Beteta & Guatemala & Privada & 1794-1807 & 5 \\
\hline D.M. Sánchez & Filipinas & Privada & 1834-1851 & 7 \\
\hline $\begin{array}{l}\text { Imprenta del Colegio } \\
\text { de Artes }\end{array}$ & Bolivia & Institucional & 1833-1838 & 4 \\
\hline \multicolumn{4}{|l|}{ Total } & 137 \\
\hline \multicolumn{5}{|c|}{$\begin{array}{l}\text { ^ Mariano Galván publicó otras dos guías de forasteros, pero en talleres diferentes debido al } \\
\text { cierre de su propia “oficina” en } 1842 .\end{array}$} \\
\hline \multicolumn{5}{|c|}{ 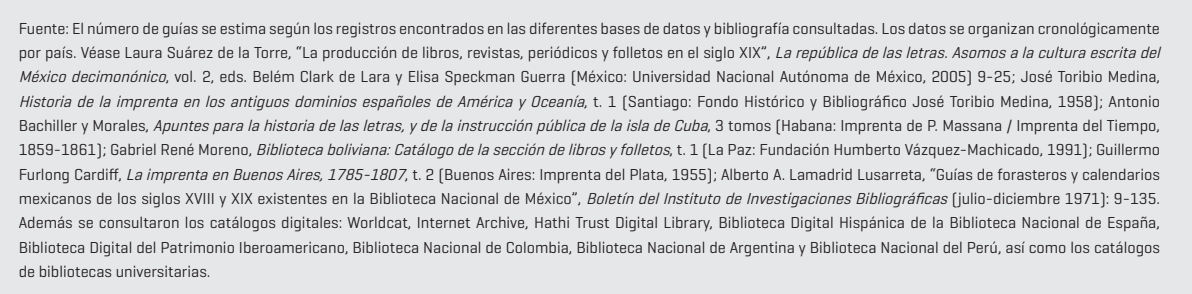 } \\
\hline
\end{tabular}


se habían obtenido por previa solicitud. El taller de los Zúñiga y Ontiveros en México, que operó entre 1760 y 1825, y la imprenta de José Masías, fundada en 1817 en Perú, son buenos ejemplos de ello: su trabajo y ganancias le aportaban a la construcción de un estatus social como empresarios reconocidos y como parte de élites que tenían poder en el mercado y en las esferas letradas. ${ }^{11}$

Además de producir documentos para la formación y la entretención al servicio de un público lector, el oficio de imprimir era (y es) también una forma de pensar y de representar la sociedad. ${ }^{12}$ Por esta misma razón, las imprentas tenían una función social que se expresaba por medio del funcionamiento interno y las jerarquías que se establecían entre las ocupaciones y especialidades, además de la imagen que proyectaban socialmente. Como veremos más adelante, la búsqueda de favores y privilegios, así como de acaparar los mercados y crear marcas sólidas asociadas con la calidad de los productos y de sus contenidos, se combinó - o se camufló- con la proyección de la idea de que las imprentas participaban en el mejoramiento y progreso de la sociedad por medio del ejercicio de una ocupación loable y de altos niveles morales. Según el bibliógrafo Juan María Gutiérrez, la vinculación de personas desprotegidas a las imprentas ofrecía la posibilidad de borrar la mácula que llevaban los niños abandonados de la ciudad por haber nacido ilegítimos; visión anclada a la concepción española del trabajo durante el periodo colonial en Hispanoamérica. Una mezcla de paternalismo y autoridad moral que desdibujaba sus límites entre la productividad y la coerción social. ${ }^{13}$

Mientras tanto, las imprentas del siglo XIX independiente y republicano proyectaron una imagen de mayor independencia y diversificación. La primera señal de ello fue la creciente oferta y demanda de libros y papeles a raíz de la declaración de la libertad de imprenta y de las crecientes dinámicas de los mercados, que permitieron que más impresores y tipógrafos convirtieran sus negocios en

11. Sobre la imprenta de los Zúñiga y Ontiveros, véase Manuel Suárez Rivera, "El negocio del libro en Nueva España: los Zúñiga Ontiveros y su emporio tipográfico (1756-1825)" (Tesis de doctorado en Historia, Universidad Nacional Autónoma de México, 2013). Posteriormente, la tesis fue publicada como Manuel Suárez Rivera, Dinastía de tinta y papel. Los Zúñiga Ontiveros en la cultura novohispana (1756-1825) (México: Universidad Nacional Autónoma de México, 2019). Sobre Mariano Galván y otros impresores particulares durante el siglo XIX en México, véase Laura Suárez de la Torre "Los impresos: construcción de una comunidad cultural. México, 1800-1855", Historias 60 (2005): 77-92. En su estudio y bibliografia de la imprenta en Lima, José Toribio Medina recoge referencias de algunos de los impresos que salieron de la imprenta de José Masías hasta 1824. José Toribio Medina, La imprenta en Lima (1584-1824), 4 tomos (Santiago de Chile: Impreso y grabado en casa del autor, 1904-1907)

12. David McKitterick, Print, Manuscript and the Search for Order, 1450-1830 (Cambridge / New York: Cambridge University Press, 2006) 166-167.

13. Juan María Gutiérrez, Bibliografia de la primera imprenta de Buenos Aires desde su fundación hasta el año de 1810 inclusive, ó catálogo de las producciones de la Imprenta de Niños espósitos, con observaciones y noticias curiosas, precedida de una biografia del virey don Juan José de Vértiz y de una disertacion sobre el orijen del arte de imprimir en América y especialmente en el Rio de la Plata (Buenos Aires: Imprenta de Mayo, 1866); R. Douglas Cope, The Limits of Racial Domination. Plebeian Society in Colonial Mexico City, 1660-1720 (Madison: University of Wisconsin Press, 1994) 94. 
empresas más competitivas (aunque no siempre sobrevivieran por un largo periodo de tiempo). ${ }^{14}$ Algunos de los anuncios comerciales muestran que los impresores desde el primer tercio del siglo XIX contaban con variados servicios de papelería, encuadernación, tipografia y edición de libros de todo tipo: literarios, de viajes, históricos, filosóficos, religiosos, científicos y económicos. Empresarios como Mariano Galván Rivera, creador del popular calendario que llevaba su nombre, Ignacio Cumplido o la Imprenta de Andrade y Escalante en México y las imprentas de José Benito Gaitán e Ignacio Borda en Colombia sacaron al mercado obras para diferentes tipos de público como las mujeres jóvenes, los niños y aprendices escolares, los hombres de letras y consumidores de lecturas especializadas. ${ }^{15}$

\section{Privilegios y monopolios editoriales}

La legislación sobre los privilegios o derechos de impresión se centra en la definición de a qué o a quiénes les corresponde la potestad de reproducir un escrito o una obra y obtener reconocimiento social y ganancias económicas por ello. A finales del siglo XVIII y principios del XIX no se puede decir que en el mundo hispánico se hablara de lo escrito y publicado como "propiedad" de un autor o de una imprenta. Estas dinámicas solo cambiaron hasta el momento en que los privilegios y licencias de impresión, regidas por los gobiernos centrales y avalados por el Santo Oficio, perdieron vigencia con la declaración de la libertad de imprenta en las Cortes de Cádiz (1810-1812). El estudio de esta forma de regular la publicación y circulación de impresos en Hispanoamérica muestra también que se trataba de una manera de controlar la difusión de ideas, así como las ganancias económicas que este negocio les representaba a los impresores y libreros; desde sus orígenes fue una cuestión moldeada por factores ideológicos y comerciales. ${ }^{16}$

La vigilancia de los contenidos y de la producción de impresos durante el siglo XVIII se hacía principalmente por el otorgamiento de licencias de impresión y de privilegios con el fin de tener mayor control sobre las obras que se publicaban tanto en España como en los reinos de ultramar. La licencia se diferenciaba del privilegio en que debía ser solicitada por todas aquellas personas que buscaran imprimir un documento. Por su parte, el privilegio "se trataba de una concesión exclusiva que otorgaba el rey a la persona -impresor, editor, librero o

14. Laura Suárez de la Torre, "Libros y editores. Las primeras empresas editoriales en el México independiente. 1830-1855”, Secuencia 46 (2000): 8.

15. En las guías de forasteros impresas en Bogotá se muestra una nutrida oferta de impresos de autores colombianos e hispanoamericanos como la gramática de Andrés Bello, otras obras de Vergara y Vergara y la urbanidad de Carreño, además de las tablas de aritmética y las obras de Antonio Nariño. José María Vergara y Vergara y José Benito Gaitán, Almanaque de Bogotá i guía de forasteros para 1867 (Bogotá: Imprenta de Gaitán, 1866); Ignacio Borda y José M. Lombana, Gran almanaque y completa guía de Bogotá (Bogotá: Imprenta de Ignacio Borda, 1886).

16. Fermín de los Reyes Gómez, El libro en España y América: legislación y censura (siglos XV-XVIII), vol. 1 (Madrid: Arco Libros, 2000) 23. 
autor- que solicitaba la gracia de ser el único con el permiso de imprimir y de vender determinada obra". ${ }^{17}$ En el caso de las imprentas, los privilegios también se otorgaban a individuos con un taller privado o a una imprenta perteneciente a una institución con el fin de obtener el monopolio de uno o un grupo de textos con sus respectivas exenciones de impuestos y de detener el fraude y la competencia. ${ }^{18}$

El taller de los Zúñiga y Ontiveros en Nueva España y la Imprenta de Niños Expósitos de Lima fueron los primeros establecimientos en obtener el privilegio de impresión de las guías de forasteros en Hispanoamérica y también en conservarlo por más de cincuenta años. La obtención de este privilegio por parte de las autoridades españolas era también indicador de algo más: al solicitar y recibir este "derecho especial", las imprentas permitían la intervención gubernamental sobre la producción de dicho impreso. ${ }^{19}$ Por este motivo podemos pensar, aun con más razones, que las guías de forasteros estaban ciertamente moderadas por las autoridades y por las leyes reformistas de los borbones y, en consecuencia, sus contenidos eran presentados de tal manera que no contravinieran las expectativas gubernamentales. Otros ejemplos de legislación se manifestaban por medio de la aclaración en la portada de las guías de que estas eran producto de una "orden superior" o que tenían "permiso de Superior Gobierno” (como las guías de forasteros del Nuevo Reino de Granada para 1793 y de Buenos Aires para 1803).

La licencia y posterior privilegio otorgado a los editores de las guías de forasteros dan cuenta de su importancia como impreso oficial y del carácter de exclusividad que su procedencia les confería. Según la solicitud hecha a finales del siglo XVIII por Felipe y Mariano de Zúñiga en México, Ignacio Beteta en Guatemala o Blas de los Olivos en Cuba, existía una preocupación por adquirir o evitar perder este impreso de la lista de productos con exclusividad, pues, dada su utilidad, podría tener buena circulación y niveles de venta. De todos modos, esto no significó que todos los impresores actuaran siempre legalmente y que gracias a esta actividad no percibieran jugosas sumas de dinero por impresos de alta demanda. De hecho, a finales del periodo colonial "el mercado de las imprentas sobrepasa las imprentas 'con licencia' y permite accesoriamente la existencia de una literatura que escapa en parte al control oficial", ${ }^{20}$

Las restricciones que controlaban este mercado no fueron un impedimento para que los impresores identificaran ciertos productos que podían ser una mina de oro para sus negocios y para ello recurrían en ocasiones a estrategias que les permitieran alcanzar ganancias significativas. Esta situación se dio con José Silva y Aguiar, el primer encargado de la Imprenta de los Niños Expósitos en el virreinato del Río de La Plata. Este impresor "sacaba provecho personal y fraudulento

17. Marcela Zúñiga Saldaña, "Privilegios para imprimir libros en la Nueva España, 1714-1803. La renta de un monopolio editorial", Estudios del Hombre 20 (2005): 60.

18. Reyes Gómez 23.

19. Reyes Gómez 30.

20. François-Xavier Guerra, Modernidad e independencias. Ensayos sobre las revoluciones hispánicas (Madrid: Ediciones Encuentro, 2009) 283. 
de la administración de la imprenta [...] registrando en los detalles contables [...] más papel del que realmente consumía para los trabajos declarados. Y además haciendo figurar en esos mismos registros más publicaciones que las que de hecho realizaba". ${ }^{21}$

Por su parte, Felipe de Zúñiga y Ontiveros obtuvo en 1774 por primera vez el privilegio de imprimir la guía de forasteros para Nueva España por un periodo de diez años. Una vez vencido este plazo, el impresor solicitó al virrey que le fuera concedido otro decenio de privilegio también con el objetivo de cederle este permiso a su hijo Mariano tras ofrecer una suma de 1,000 pesos. No obstante, en marzo de 1793 el virrey anunció a la Corte que Zúñiga no había cumplido aún con ese requisito, la familia logró obtener al menos otros 10 años de privilegio por parte del virrey Antonio María de Bucareli. ${ }^{22}$ Es más, el propio Felipe de Zúñiga llegó a constatar que "en los calendarios, pronósticos y guía del año de 1775 busqué, horros los gastos, 1.700 pesos cuya ganancia subió más que los otros años por el privilegio que conseguí en el kalendario chico y que la guía se vendieron más y a mayor precio". ${ }^{23}$

El carácter oficial de las guías de forasteros encargadas por los gobiernos virreinales representaba un estatus social y de oficio que contaba con el beneplácito de las autoridades y con el beneficio de las ganancias económicas. Así lo demuestra, por ejemplo, el tercer impresor de la Habana, Blas de los Olivos, quien siguiendo la sugerencia del capitán general de Cuba, el Conde de Ricla envió a la Península en 1764 una detallada propuesta para obtener el privilegio de impresión de las guías de forasteros, ${ }^{24}$ que incluía:

Que para que el producto sea maior se le concederà el Privilegio esclusivo de Imprimir para toda la Isla, el Cathecismo de padre Ripalda, Catón Christiano, Almanaques y Cartillas, con ecstencion al de Gazetas, Mercurios, Guias de Forasteros, y otros Papeles, que en los Reynos, ò por la secretaria de aquella Capitania General se le franqueen: Que para hacer mas respetàble la Impresion, solicitarà el enunciado Governador se le despàche el Titulo de Impresor de V.M. y en el interin, le conceda el de la Ecspresada Capitania General: que consiguiente al referido Titulo, seria en su cargo imprimir los Autos de buen govierno y todos los Papeles que pertenezcan al Real Servicio, gozando la Real Hacienda el contingente apropiado de estos Papèles que se vendan al Publico. ${ }^{25}$

21. Graciela Batticuore, "Entre legislaciones y prácticas: el comercio de libros en el Buenos Aires finicolonial" (Ponencia, Primer Coloquio Argentino de Estudios sobre el Libro y la Edición, Universidad Nacional de La Plata, 2012). http://www.memoria.fahce.unlp.edu.ar/trab_eventos/ev.1920/ev.1920.pdf (20/08/2019).

22. Zúñiga Saldaña 73.

23. Citado en Suárez Rivera, "El negocio del libro" 80.

24. José Toribio Medina, La imprenta en La Habana (1707-1810). Notas bibliográficas (Santiago de Chile: Imprenta Elzeviriana, 1904) XIV-XV.

25. "Consultas y pareceres dados al Rey en asuntos de gobierno de Indias", 1766. AHN, Madrid, Diversos y Colecciones, códice 754 
Aunque la solicitud fue rechazada por el Consejo de Indias, el proyecto que se trazó el impresor de La Habana comprendía un amplio espectro de publicaciones que incluía textos de enseñanza y doctrina cristiana, de consulta general y de comunicaciones oficiales del gobierno. Este ambicioso plan demuestra cómo el monopolio de la impresión por medio de los privilegios establecía jerarquías, podía entregar utilidades significativas a los impresores y permitía reducir notoriamente las posibilidades de acción de la competencia.

La existencia de licencias y privilegios hasta el final del periodo colonial permitió que se configurara la idea de la "propiedad" en relación con la obra creada. Estos permisos suministrados por la Corona española tenían una sólida relación con el poder gubernamental como mecanismo de control y de unificación de las formas de pensamiento. En consecuencia, la censura era una herramienta eficaz para "corregir" las obras que se salían del discurso hegemónico instaurado por la monarquía. ${ }^{26}$ El fin de la institución del Santo Oficio tras las Cortes de Cádiz y el decreto de la libertad de imprenta dieron paso para la introducción de cambios progresivos en la forma de legislar y de concebir los derechos de autor. El poder que ejercieron las autoridades monárquicas sobre la cultura del impreso, en este caso con las guías de forasteros, no desapareció sino hizo una transición a otras formas de dominación y control. Así, la formación del Estado nacional trajo consigo intereses gubernamentales o de las élites letradas (que en ocasiones eran la misma figura) que encontraron en las guías de forasteros un medio de difusión de información útil y efectivo: su principal cualidad era su presencia en la cultura del impreso y el conocimiento que los lectores tenían de este género desde tiempo atrás.

\section{Qué se necesita para editar una guía de forasteros}

Los impresos no son el producto de la acción espontánea de un editor o autor, sino que, por el contrario, requieren de la participación y articulación de diferentes agentes en su proceso de producción, circulación, venta y comunicación con el editor / autor. El ejercicio de editar una guía de forasteros tenía muchos frentes que atender, pues los contenidos no dependían únicamente de la pluma del editor. Era un "cadáver exquisito" en el cual el coordinador de la guía incluía algunos datos que ya poseía, creaba otros por medio de la consulta de diversos materiales y reunía lo que le llegaba de las oficinas de las que dependía para completar su trabajo. El criterio del editor era fundamental, pues, según su visión de mundo, las expectativas de quienes encargaban las guías (en caso de ser el gobierno) y las capacidades de la imprenta estas mostraban resultados diversos y a veces dispares.

Como ya hemos visto, el esqueleto básico de las guías de forasteros - el almanaque y el directorio - se componía a partir de la recolección de datos: nombres de dependencias y oficinas, nombres de funcionarios y sus cargos (a veces con la

26. Manuel Lucena Giraldo, "Historiografia y censura en la España ilustrada", Hispania LXV.221 (2005): 986. 
dirección de su domicilio), datos cronológicos, fechas de los nacimientos de la nobleza española y, en algunos casos, números de bautismos, matrimonios y muertes en parroquias o de enfermos en los hospitales. La consecución de esta información se lograba con la consulta de diferentes tipos de fuentes y con la presión ejercida sobre quienes debían proveerla. En consecuencia, esta actividad motivaba una serie de diálogos entre diferentes agentes que participaban en la producción y recepción de la guía, principalmente lectores, editores / autores y proveedores de información. Las guías de forasteros surgieron en España como un proyecto editorial de iniciativa particular que terminó siendo acogido por el rey a mediados del siglo XVIII para la península ibérica, y posteriormente para los reinos de ultramar. ${ }^{27} \mathrm{Se}-$ gún lo expresan algunas guías de forasteros hispanoamericanas de aquel siglo, eran los virreyes los encargados de decretar cómo y cuándo debía dirigirse la información a la persona encargada de editar estos impresos en los reinos de América. Por lo tanto, fue común encontrar en las guías de forasteros un mensaje del editor / autor dirigido a los lectores en el que solicitaba el envío puntual de la información con el fin de completar la guía para el año siguiente.

En principio, existían tres tipos de proveedores de información: 1) los materiales impresos que eran consultados por los editores / autores y elegidos según sus necesidades, intereses y criterios editoriales; 2) los empleados oficiales y encargados de remitir la información solicitada para la elaboración de las guías de forasteros; y 3) los lectores o usuarios de las guías. Podríamos pensar que los funcionarios eran también lectores o usuarios de las guías, dado que los autores se dirigían a ellos por medio de este impreso (lo que significa que al menos los autores de las guías sí los consideraban como tal); sin embargo, su tarea estaba mediada por su posición en las instituciones gubernamentales. Por su parte, los proveedores de información particulares eran lectores que por interés propio (por solidaridad o con el fin de que esto los beneficiara personal o socialmente) les dirigían comunicaciones a los editores / autores para que en la siguiente edición de las guías se incluyera, corrigiera, aumentara o completara la información que podía ser de interés o utilidad.

Asimismo, estos proveedores de información no aparecían de manera espontánea y, como veremos en algunos ejemplos, su función surgía a raíz de un acto comunicativo entre ellos y el editor / autor por medio de las guías de forasteros o de la prensa. Esta es una de las principales razones por las cuales podemos considerarlos un agente más en el circuito de comunicaciones propuesto por Darnton: porque participan en el proceso de elaboración de las guías y también de la construcción del sentido de sus discursos. Finalmente, es posible suponer que no toda la información que le llegaba al autor remitida por estos proveedores de información era en efecto utilizada para la elaboración de la guía. Podía suceder que los datos no concordaran con los criterios de elaboración, con las dinámicas de poder establecidas tácitamente o con la representación social, política y cultural que buscaba el editor / autor. ${ }^{28}$

27. Cuellar Wills 89-90.

28. Esta deducción se fundamenta en la naturaleza de la historia de la cultura escrita definida por 
En el Calendario manual y guia de forasteros de México para 1792 aparece en la penúltima página la siguiente nota:

El Exmo. SeñorVirrey Conde de Revilla Gigedo por Decreto de 12 de Enero del año de 1791 resolvió, que para que esta Guia de Forasteros salga siempre con el debido arreglo, todos los Tribunales y Cuerpos de que se compone dirijan á su Autor sus respectivas Listas en los quince primeros dias del mes de Diciembre de cada año, para que pudiendose coordinar en los restantes, se verifique su publicacion en principios de Enero. ${ }^{29}$

A pesar de esta orden, los espacios en blanco en algunas secciones de las guías demostraban año tras año que alguna dependencia o algún nombre había hecho falta. Esta ausencia de información podía darse por dos contingencias principales: o los datos no llegaban a tiempo o no se podían verificar, y la guía se imprimía antes de que se eligieran algunos funcionarios del territorio al inicio del año. En ambos casos existía una restricción de tiempo que les impedía a los editores intervenir el texto según su libre albedrío; tenían una estructura que completar, pero no dependía únicamente de ellos que se llevara a cabo. Es en este sentido que el proveedor de información, un agente del cual depende especialmente el editor / autor para poder completar su trabajo, es fundamental en el circuito de Darnton.

Son varios los ejemplos en los que los editores de las guías explicaban o justificaban la ausencia de información. Esto sucedía generalmente en notas en medio o al final del impreso y posteriormente se empezó a usar la presentación o introducción. En la Guía de Forasteros del Virreynato de Buenos-Ayres para el año de 1803, José Joaquín de Araujo explicaba al llegar a la sección correspondiente a la Real Audiencia de Charcas: "No se ha puesto la fundación, situacion, y privilegios de esta Ciudad, conforme executa en las demas Intendencias, porque la cortetad [sic] del tiempo que ha mediado para la formacion de esta Guia no ha dado lugar á verificarlo como corresponde, por lo que se executara para el siguiente año".30

A partir de esta reflexión, sumada al hecho de que en la mayoría de las guías seriadas se repetían algunos datos como nombres de funcionarios o descripciones de dependencias, se deduce que los editores / autores "reciclaban" información. Incluso, el hecho de no tenerla se convertía en una dificultad mayor porque los obligaba a depender de terceros para poder completar los espacios en blanco. Esta situación es una oportunidad para revisar las dinámicas de poder que se establecían en el proceso de elaboración, impresión, distribución y recepción de las guías. Si

Robert Darnton, quien se pregunta, entre otras cosas, cuál es la conexión entre la cultura y la estratificación social. Darnton 65. En el análisis histórico de las guías de forasteros la pregunta es fundamental y, cuando se trata de crear una representación estructurada y jerárquica política, social y comercialmente de una sociedad, el autor / editor se convierte en un agente de poder.

29. Felipe de Zúñiga y Ontiveros, Calendario manual y guia de forasteros en México, para el año de 1792 bisexto (México: Felipe de Zúñiga y Ontiveros, [s.f.]).

30. José Joaquín de Araujo, Guía de Forasteros del Virreynato de Buenos-Ayres para el año de 1803 (Buenos Aires: Real Imprenta de los Niños Expósitos, 1802) 59. 
bien es claro que las guías de forasteros se imprimían y se leían generalmente entre las élites letradas de las sociedades hispanoamericanas de finales del siglo XVIII y en el transcurso del siglo XIX, es interesante ver cómo la capacidad de los autores de llevar a buen término la guía no dependía solo de sí mismos ni de los encargados del taller. Los proveedores de información tenían también un gran poder sobre este proceso, al punto que, si no enviaban la información que estaba a su cargo o que conocían, la guía podía quedar incompleta o no salir a tiempo. Esa era la ironía trágica de la mayoría de las guías de forasteros: existían principalmente por y para un funcionariado, el cual resultaba ser el mismo que en muchos casos obstaculizaba su exitosa elaboración y finalización.

Ese poder adquirido convierte entonces a los proveedores de información en agentes con la misma importancia que los libreros, los vendedores o los impresores, de quienes también dependía en gran medida el éxito y la circulación de las guías. Su participación era silenciosa y ciertamente fundamental para los autores, tal como lo expresa el siguiente ejemplo de 1851:

\begin{abstract}
ADVERTENCIA FINAL
Por la premiosa exijencia que se nos ha hecho de estos materiales a fin de no retardar la publicacion de la gUIA DE FORASTEROS EN LA NUEVA GRANADA, hemos dejado en blanco algunas cosas, principalmente en la relacion de los miembros del Congreso, cuyos datos apenas empezamos a recibir ahora. Por igual motivo hemos dejado de poner los nombres de Diputados a la Cámara de provincia, vocales de Cabildo, alcaldes, jueces parroquiales, empleados de la sociedad Democrática y Escuela Republicana, porque terminando en el presente año su periodo los que ejercen estos destinos; hasta fines de diciembre y principios de enero y aun mas tarde-no podrán saberse los nuevos nombramientos que se hagan.

Si se acoje bien nuestro ensayo y Dios nos permite, para 1853 podremos brindar al público una obra completa de este jénero, cuya utilidad es conocida, por fortuna, de nuestros compatriotas desde la rejencia delVirei Ezpeleta. ${ }^{31}$
\end{abstract}

Autores más arriesgados como el argentino Antonio Pillado usaron la presentación de su guía para expresar su inconformidad con la información que no llegó y para calificar la pobreza de trabajo de quienes estaban encargados de hacerlo. Para la segunda mitad del siglo XIX el trabajo de recolección de información en las guías se convirtió no solo en una tarea de organización, sino también de selección para conformar un material que resultara útil, además, interesante a los lectores. Por lo tanto, la función social de los editores / autores de las guías consistía en crear representaciones espaciales, sociales, políticas y culturales de los territorios reseñados según unas expectativas establecidas, por una parte, por el género de las guías como tradición editorial y, por otra, por el criterio de los encargados de editarlas. En palabras de Antonio Pillado la situación se resume así:

31. Guia de forasteros en la Nueva Granada ([Bogotá]: [s.e.], [1851]) 67. 
Que los primeros renglones de este libro espresen nuestro agradecimiento á todas las personas que, en vez de los informes ó noticias que les pedimos, nos han favorecido con artículos interesantes para ilustrar sus páginas. Su buena voluntad contrasta notablemente con la inercia de otros, pues la deficiencia de esta publicacion en algunos puntos, proviene casi siempre de la flojedad de los datos que hemos alcanzado. ${ }^{32}$

La codependencia del envío de información por parte de los editores / autores era tal que en muchas ocasiones la falta de respuesta o de cumplimiento retrasó los ritmos y fechas de publicación de las guías, lo que los obligó a hacer esperar al público hasta que los contenidos estuvieran más completos para poder imprimirlas o dejarlos con la duda sobre quiénes conformaban ciertas dependencias u oficinas.

\section{Ritmos de publicación de las guías de forasteros}

Como en el caso de las guías de forasteros de España, las hispanoamericanas se editaban con el propósito de que al año siguiente saliera una nueva edición, mejorada y corregida, pero esto no sucedió siempre a pesar de que la intención fuera otra. Por lo tanto, las guías de forasteros se concebían para una vida de 365 días que se expresaba en el título cuando se incluía "para el año de". Pasado este tiempo, los lectores esperaban una nueva edición y por eso existía una alta posibilidad de que el ejemplar "vencido" terminara siendo usado para un fin diferente al de la lectura o la consulta. Este carácter de objeto prescindible al final de un periodo de uso permitió que se conservaran, en casos como Guatemala y Puerto Rico, pocos ejemplares a los que los lectores de hoy pueden acceder públicamente. El reducido número de guías de forasteros que se puede consultar en la actualidad tiene diferentes motivos relacionados tanto con las prácticas de lectura como con la cultura del impreso. El tiraje tan difícil de conocer en el análisis histórico de las guías y la continuidad de impresión de estas demuestran en qué países circularon y se requirieron con mayor insistencia. ${ }^{33}$

Muchas guías de forasteros omitieron el año de su publicación en la portada por lo cual es dificil establecer si se imprimieron a finales del año anterior o a principios del reseñado en los contenidos. Asumir que este se puede deducir

32. Antonio Pillado, Diccionario de Buenos Aires ó sea guia de forasteros (Buenos Aires: Imprenta del Porvenir, 1864) [s.p.].

33. El hecho de que las guías de forasteros hayan tenido una presencia relevante en la cultura de las formas impresas en Hispanoamérica no significa necesariamente que su producción haya sido abundante. Si se comparan los datos con el número de registros, años y ciudades que las imprimieron, es notoriamente menor a la producción de periódicos o de manuales escolares desde finales del siglo XVIII y durante el XIX; sin embargo, hay que tener en cuenta que no todos los impresos van dirigidos siempre al mismo tipo de público. Las guías de forasteros eran producidas por y para un público de élite, que originalmente se dibujó como un círculo de personas que requería de información para resolver o adelantar sus negocios, por lo tanto, es muy probable que el tiraje (desconocido aún) fuera significativamente menor al de los periódicos, que se pensaban para una difusión más amplia. 
por el título puede llevar a resultados y descripciones bibliográficas equívocas, además de suponer que todas las guías se editaban e imprimían bajo ritmos y calendarios estandarizados sin la intervención de variables como la escasez de papel, la inestabilidad política y social, los costos de impresión y, sobre todo, la falta de información. ${ }^{34}$ Es dificil constatar que las prácticas de impresión y edición tuvieran un ritmo tan uniforme e infalible, pues, como lo plantea Darnton en su circuito de comunicaciones, la decisión de publicar un impreso en determinado momento no dependía solo del autor o del editor. El retraso de alguno de los agentes comprometidos en el proceso también influía necesariamente en los tiempos de producción y circulación del impreso.

En un aviso en la Gazeta de México del 18 de diciembre de 1787, el editor se disculpaba por la demora en la circulación, pues "la Guia de Forasteros no se publicará hasta pasado el día de Reyes, por quanto las circunstancias ocurrentes y las adiciones que lleva exigen para su perfeccion mas tiempo del que ha sido regular". ${ }^{35}$ Asimismo, la sección de avisos de la gaceta del martes 22 de enero de 1793 anunciaba que "el Viernes inmediato se publicará la Guia de Forasteros"; ya había corrido casi por completo el primer mes del año y el impreso aún no circulaba. ${ }^{36}$ No se puede desconocer que la intención original de los editores era sacar al mercado las guías de forasteros desde el inicio del año en curso, pues el hecho de que incluyeran un almanaque así lo comprometía. Sin embargo, en la práctica hubo casos como los de los Zúñiga y Ontiveros, impresores experimentados, o como en la Guía de forasteros de Venezuela impresa por Gallagher y Lamb y editada por Andrés Bello en los que no siempre se cumplieron las fechas estipuladas por situaciones adversas: correcciones de última hora, retrasos del autor, escasez de materiales o de fondos o ausencia del mismo autor, entre otros.

La intención de publicar estos impresos puntualmente antes de que finalizara el año implicaba que con el género de las guías venía también un ritmo de lectura implícito o al menos deseado por quienes las producían. La idea era que fueran útiles durante todo el año y que pudieran solucionar las dudas y alimentar los intereses de los lectores que fueran surgiendo. No obstante, en la práctica vemos que la situación era diferente para el circuito de comunicaciones en el proceso de elaboración, impresión, circulación y usos de las guías. Varios autores expresan

34. Existe en varios catálogos de bibliotecas públicas y universitarias la tendencia a dar como año de publicación de las guías de forasteros el anterior al que aparece en el título sin mencionar alguna referencia bibliográfica que efectivamente lo constatara. Aunque puede parecer un asunto menor, en el análisis histórico de un género como las guías de forasteros estos datos pueden cambiar el curso del estudio de las prácticas de impresión y de la relación entre los autores / editores de las guías y los demás agentes que intervenían en el circuito de comunicaciones.

35. Gazeta de Mexico, compendio de noticias de Nueva España, t. 2 (México: Felipe de Zúñiga y Ontiveros, [s.f.]) 468.

36. Gazeta de Mexico, compendio de noticias de Nueva España, t. 5 (México: Imprenta de los herederos de don Felipe de Zúñiga y Ontiveros, [s.f.]) 252. 
su idea de tener recogida la mayor cantidad de información antes de octubre o noviembre para alcanzar a imprimir en diciembre o a principios de enero.

Un caso interesante se dio con la guía de Puebla para 1852 de Juan Nepomuceno del Valle. La edición pretendía abarcar todos los establecimientos comerciales, instituciones, oficinas, servicios, medios de transporte y diversiones de la ciudad. Sin embargo, la guía, un voluminoso ejemplar de 460 páginas, no salió a la venta al principio del año, sino, según cuenta Del Valle, dueño de su propio taller de imprenta, "se ha estado publicando por entregas semanarias, y cada año saldrá un cuadernillo conteniendo las variaciones que sean necesarias por el cámbio de empleados, etc.". ${ }^{37} \mathrm{Su}$ estrategia consistió en sortear las dificultades de reunir tal cantidad de información y optó por hacer una guía de forasteros "por entregas" a la manera de una novela. Aunque su proyecto de actualizar la información anualmente parece no haber prosperado, este ejemplo es relevante por la manera en la que el autor pretendía transformar el ritmo tanto de producción como de prácticas de lectura por medio de la búsqueda de nuevas estrategias para garantizar una clientela de las guías de forasteros a lo largo del año.

Fue por medio de las guías y de la prensa como progresivamente los editores / autores fueron revelando en sus contenidos la forma como recogían la información. Además de las dependencias oficiales encargadas de remitir datos que hubieran cambiado, los editores / autores requerían del conocimiento del calendario cristiano para la elaboración del almanaque, de mediciones astronómicas y, en el caso la mayoría de las guías del Perú de finales del siglo XVIII y principios del XIX, consideraciones de corte científico para la introducción. Por esto la lectura de la prensa y de otros impresos americanos y europeos resultaba esencial para la elaboración de las guías de forasteros, lo cual era un ejercicio editorial dispendioso y a contrarreloj. La participación de los "informantes" en su elaboración se complementaba con otro tipo de conocimientos como el uso de datos consignados en los "Estados generales", informes estadísticos, reflexiones históricas o descripciones.

Los Zúñiga fueron insistentes con sus demandas y al final de año solían publicar también en la Gazeta de México, editada por Manuel Antonio Valdés, un aviso en el que solicitaban el envío de los datos de las dependencias. La cortesía pasaba a la frustración y se hacía notorio que la dependencia de otros era un obstáculo en el cumplimiento de las fechas y la precisa realización del propósito editorial:

El Autor de la Guía de Forasteros suplica á los Señores Gefes principales de los Juzgados, Oficinas, y demas Cuerpos autorizados, de que ella se compone, se sirvan de mandar á uno de sus Subalternos pase á Imprenta la respectiva nomina de los Sugetos empleados, con las calles de sus moradas, pues solo asi se podrá conseguir el arreglo que siempre se ha deseado; porque colectar las noticias á fuerza de preguntas, á mas de ser casi imposible el acierto, resultan diminutas, y tal

37. Juan N. del Valle, Guia de Forasteros de la capital de Puebla, para el año 1852 (Puebla: Imprenta del Editor, [1851]) 415. 
vez inciertas; estendiendose asimismo la súplica á que las personas que no hubieren ocurrido en tiempo (que es hasta fin de Noviembre) se sirvan de no reclamarle si despues notaren en su lugar, empleo ó morada algun defecto. ${ }^{38}$

Felipe de Zúñiga reclamaba puntualidad y eficiencia de las dependencias y estaba curándose en salud. Además de los errores detectados en la guía antes de ponerla a circular, que aparecían en una sección de "erratas", "aclaraciones" o "adiciones", el editor / autor utilizó el espacio provisto por la Gazeta que se imprimía en su taller para publicar otras enmiendas realizadas conforme los lectores las iban solicitando. Sin embargo, con esta intervención deja claro que en muchas ocasiones los errores o confusiones cometidos en la guía de forasteros no eran únicamente responsabilidad de quienes reunían la información, sino de quienes dejaban de corregirla o rectificarla antes de enviarla.

En la "Nota" publicada en las primeras guías de forasteros peruanas de 1781, 1783, 1784 y 1786, Cosme Bueno le solicitaba a los lectores que llenaran a mano "como se practica en la Guia de Mèxico" los datos que no alcanzaron a incluirse. ${ }^{39}$ Además de destacar la carencia de información en algunas secciones, Cosme Bueno dejaba implícita la posibilidad de que existiera también un circuito de comunicaciones entre las guías de forasteros, que empezaba con el modelo de Felipe de Zúñiga en Nueva España y continuaba por medio de la consulta de almanaques de Europa, de cifras recogidas por oficinas de los virreinatos y de prensa y otros impresos que servían para complementar prólogos, calendarios, noticias históricas o cronologías.

Estos mismos canales de comunicación que construyeron las guías de forasteros sirvieron para que su función social no se limitara a crear listas y servir de directorio para funcionarios. El gobierno español propuso unos parámetros que las guías debían seguir y los editores / autores con el fin de cumplir su tarea buscaron los medios y recursos necesarios para lograrlo. En este proceso, crearon con las guías de forasteros una suerte de "bibliotheca" para extranjeros y locales que no solo se componía de nombres, sino de diálogos con otras formas de producción escrita en las que se incluían temas relacionados con la geografía, la estadística, la medicina, la astronomía y la historia natural.

\section{Para cerrar}

La historia de la cultura de las formas impresas se compone de muchas variables que no se alcanzan a abarcar en su totalidad en este artículo, relacionadas, en buena medida, con el circuito de comunicaciones de Darnton: los suministros materiales, el transporte de los impresos o los lugares donde se podían comprar las guías y otro tipo de textos. Sin embargo, el análisis de algunos de sus componentes esenciales

38. Gazeta de Mexico, compendio de noticias de Nueva España, t. 1 (México: Felipe de Zúñiga y Ontiveros, [s.f.]) 410 .

39. Cosme Bueno, El conocimiento de los tiempos; efemeride del año de 1781, primero despues del bisiesto ([Lima]: Imprenta Real, 1780) [s.p.]. 
como la legislación, la forma de comercialización y los recursos necesarios para la composición de sus discursos muestran que las guías eran impresos que, como muchos otros, participaban de dinámicas comerciales, sociales y culturales del periodo estudiado. Las guías de forasteros, entonces, sirven como ejemplo de cómo la cultura de las formas impresas en el periodo final de las reformas borbónicas y en las primeras décadas de las repúblicas americanas recogieron prácticas comerciales y culturales asociadas al mercado de los impresos y a las formas de representación política y social por medio de la letra impresa. Si bien el circuito de comunicaciones de Darnton presenta sus limitaciones para la comprensión del contexto y de la diferencia de relaciones que existen entre la Francia del siglo XVIII y los reinos españoles de ultramar, es una opción para cuestionar y analizar cómo funcionaron las dinámicas del mercado de los impresos en sociedades que pretendían establecer órdenes jerárquicos como los que regían en España. Es más, sirve también para revisar qué aportes adicionales hicieron las guías de forasteros a las comunicaciones entre diferentes agentes del mercado como editores / autores, libreros, lectores y proveedores de información, así como a la conformación y consolidación del mercado de los impresos en Hispanoamérica.

\section{Fuentes}

\section{Manuscritas}

Archivo Histórico Nacional, Madrid (AHN)

Diversos y Colecciones

\section{Impresas}

Araujo, José Joaquín de. Guía de Forasteros del Virreynato de Buenos-Ayres para el año de 1803. Buenos Aires: Real Imprenta de los Niños Expósitos, 1802.

Bachiller y Morales, Antonio. Apuntes para la historia de las letras, y de la instrucción pública de la isla de Cuba. 3 Tomos. Habana: Imprenta de P. Massana / Imprenta del Tiempo, 1859-1861.

Borda, Ignacio y José M. Lombana. Gran almanaque y completa guía de Bogotá. Bogotá: Imprenta de Ignacio Borda, 1886.

Bueno, Cosme. El conocimiento de los tiempos; efemeride del año de 1781, primero despues del bisiesto. [Lima]: Imprenta Real, 1780.

Gazeta de Mexico, compendio de noticias de Nueva España. Tomo 1. México: Felipe de Zúñiga y Ontiveros, [s.f.].

Gazeta de Mexico, compendio de noticias de Nueva España. Tomo 2. México: Felipe de Zúñiga y Ontiveros, [s.f.].

Gazeta de Mexico, compendio de noticias de Nueva España. Tomo 5. México: Imprenta de los herederos de don Felipe de Zúñiga y Ontiveros, [s.f.].

Guia de forasteros en la Nueva Granada. [Bogotá]: [s.e.], [1851]. 
Gutiérrez, Juan María. Bibliografia de la primera imprenta de Buenos Aires desde su fundación hasta el año de 1810 inclusive, ó catálogo de las producciones de la Imprenta de Niños espósitos, con observaciones y noticias curiosas, precedida de una biografia del virey don Juan José de Vértiz y de una disertacion sobre el orijen del arte de imprimir en América y especialmente en el Rio de la Plata. Buenos Aires: Imprenta de Mayo, 1866.

Pillado, Antonio. Diccionario de Buenos Aires ó sea guia de forasteros. Buenos Aires: Imprenta del Porvenir, 1864.

Valle, Juan N del. Guia de Forasteros de la capital de Puebla, para el año 1852. Puebla: Imprenta del Editor, [1851].

Vergara y Vergara, José María y José Benito Gaitán. Almanaque de Bogotá i guía de forasteros para 1867. Bogotá: Imprenta de Gaitán, 1866.

Zúñiga y Ontiveros, Felipe de. Calendario manual y guia de forasteros en México, para el año de 1792 bisexto. México: Felipe de Zúñiga y Ontiveros, [s.f.].

\section{Bibliografía}

Batticuore, Graciela. "Entre legislaciones y prácticas: el comercio de libros en el Buenos Aires finicolonial". Ponencia, Primer Coloquio Argentino de Estudios sobre el Libro y la Edición, Universidad Nacional de La Plata, 2012. http://www.memoria.fahce.unlp.edu.ar/trab_eventos/ev.1920/ ev.1920.pdf (20/08/2019).

Chartier, Roger. "Lecturas y lectores 'populares' desde la época clásica hasta el Renacimiento". Historia de la lectura en el mundo occidental. Dirs. Guglielmo Cavallo y Roger Chartier. México:Taurus, 2012.

Cope, R. Douglas. The Limits of Racial Domination. Plebeian Society in Colonial Mexico City, 1660-1720. Madison: University of Wisconsin Press, 1994.

Cuellar Wills, Lina. "Hacia una definición y caracterización de las guías de forasteros en América hispana, 1761-1893”. Anuario Colombiano de Historia Social y de la Cultura 46.1 (2019): 85-122.

Darnton, Robert. “What Is the History of Books?”. Daedalus 111.3 (1982): 65-83. Furlong Cardiff, Guillermo. La imprenta en Buenos Aires, 1785-1807. Tomo 2. Buenos Aires: Imprenta del Plata, 1955.

Guerra, François-Xavier. Modernidad e independencias. Ensayos sobre las revoluciones hispánicas. Madrid: Ediciones Encuentro, 2009.

Guerra, François-Xavier y Annick Lempérière. "Introducción”. Los espacios públicos en Iberoamérica. Ambigüedades y problemas, siglos XVIII y XIX. Eds. François-Xavier Guerra y Annick Lempérière. México: Centro Francés de Estudios Mexicanos y Centroamericanos / Fondo de Cultura Económica, 1998.

Guibovich Pérez, Pedro M. "Los espacios de los libros en el Perú colonial”. Lexis XXVIII.1-2 (2003): 179-190.

Lamadrid Lusarreta, Alberto A. "Guías de forasteros y calendarios mexicanos de los 
siglos XVIII y XIX existentes en la Biblioteca Nacional de México”. Boletín del Instituto de Investigaciones Bibliográficas (julio-diciembre 1971): 9-135.

Lucena Giraldo, Manuel. "Historiografia y censura en la España ilustrada”. Hispania LXV.221 (2005): 973-990.

McKitterick, David. Print, Manuscript and the Search for Order, 1450-1830. Cambridge / New York: Cambridge University Press, 2006.

Medina, José Toribio. Historia de la imprenta en los antiguos dominios españoles de América y Oceanía. Tomo 1. Santiago: Fondo Histórico y Bibliográfico José Toribio Medina, 1958.

- La imprenta en La Habana (1707-1810). Notas bibliográficas. Santiago de Chile: Imprenta Elzeviriana, 1904.

. La imprenta en Lima (1584-1824). 4 Tomos. Santiago de Chile: Impreso y grabado en casa del autor, 1904-1907.

Moreno, Gabriel René. Biblioteca boliviana: Catálogo de la sección de libros y folletos. Tomo 1. La Paz: Fundación Humberto Vázquez-Machicado, 1991.

Rama,Ángel. La ciudad letrada. Santiago: Tajamar Editores, 2004.

Reyes Gómez, Fermín de los. El libro en España y América: legislación y censura (siglos XV-XVIII). Volumen 1. Madrid:Arco Libros, 2000.

Silva, Renán. Los ilustrados de Nueva Granada, 1760-1808. Genealogía de una comunidad de interpretación. Bogotá: Banco de la República / Fondo Editorial Eafit, 2002.

Suárez de la Torre, Laura. "La producción de libros, revistas, periódicos y folletos en el siglo XIX”. La república de las letras. Asomos a la cultura escrita del México decimonónico. Volumen 2. Eds. Belém Clark de Lara y Elisa Speckman Guerra. México: Universidad Nacional Autónoma de México, 2005.

. "Libros y editores. Las primeras empresas editoriales en el México independiente. 1830-1855”. Secuencia 46 (2000): 5-20.

. "Los impresos: construcción de una comunidad cultural. México, 18001855”. Historias 60 (2005): 77-92.

Suárez Rivera, Manuel. Dinastía de tinta y papel. Los Zúñiga Ontiveros en la cultura novohispana (1756-1825). México: Universidad Nacional Autónoma de México, 2019.

. "El negocio del libro en Nueva España: los Zúñiga Ontiveros y su emporio tipográfico (1756-1825)." Tesis de doctorado en Historia, Universidad Nacional Autónoma de México, 2013.

Zúñiga Saldaña, Marcela. "Privilegios para imprimir libros en la Nueva España, 1714-1803. La renta de un monopolio editorial". Estudios del Hombre 20 (2005): 59-86. 